\title{
VIGOR DE SEMENTES E ANÁLISE DE CRESCIMENTO DE AVEIA PRETA ${ }^{1}$
}

\author{
Luis Osmar Braga Schuch; Jorge Luiz Nedel ${ }^{2,3}$; Francisco Neto de Assis ${ }^{2,3} ;$ Manoel de Souza \\ Maia $^{2}$ \\ ${ }_{3}^{2}$ Depto. de Fitotecnia - FAEM/UFPel, C.P. 354 - CEP: 96001-970 - Pelotas, RS. \\ ${ }^{3}$ Bolsista CNPq. \\ *Autor correspondente<lobs@ufpel.tche.br>
}

\begin{abstract}
RESUMO: Este estudo foi conduzido no município de Capão do Leão, RS, Brasil, com o objetivo de avaliar o efeito do vigor das sementes sobre a evolução do crescimento de duas cultivares de aveia preta (Avena strigosa Schreb), bem como verificar possíveis interações com a população de plantas (150, 300 e 450 pl $\mathrm{m}^{-2}$ ). Diferenças no vigor das sementes e na população de plantas provocaram variação na produção de matéria seca durante o período vegetativo da cultura. Os efeitos reduziram-se progressivamente com o avanço na estação de crescimento, não mais se manifestando por ocasião da antese. Os níveis extremos de vigor de sementes e de população de plantas produziram diferenças de $410 \mathrm{~kg} \mathrm{ha}^{-1}$ e $480 \mathrm{~kg} \mathrm{ha}^{-1}$ de matéria seca, respectivamente, aos 75 dias após a emergência, sendo essas diferenças devidas a efeitos sobre a taxa de crescimento da cultura. Ocorreu efeito compensatório da população de plantas sobre a produção de matéria seca, de modo que o efeito do baixo vigor de sementes pôde ser compensado pela elevação da população de plantas; quanto mais baixo o nível de vigor das sementes, maior a necessidade do aumento da população de plantas. Sementes de alto vigor compensaram os efeitos das baixas populações de plantas.
\end{abstract}

Palavras-chave: Avena strigosa, rendimento biológico, área foliar, taxa de crescimento

\section{SEED VIGOR AND GROWTH ANALYSIS OF BLACK OATS}

\begin{abstract}
This study was carried out in Capão do Leão, RS, Brazil, with the objective of evaluating the effect of seed vigor on the growth of two cultivars of cultivated black oats (Avena strigosa Schreb), as well as to verify possible interactions with plant population $\left(150,300\right.$ and $450 \mathrm{pl} \mathrm{m}^{-2}$ ). Seed vigor and plant population affected dry matter production during the vegetative period. The effects were reduced progressively in the growing season, with no more difference after anthesis. The extreme levels of seed vigor and plant population produced differences in dry matter yield of $410 \mathrm{~kg} \mathrm{ha}^{-1}$ and $480 \mathrm{~kg} \mathrm{ha}^{-1}$, respectively, at the 75th day after emergence, these effects were due to differences in crop growth rates. A compensatory effect of the plant population on dry matter production was verified, so that the effect of low seed vigor could be compensated by an increase in plant population; the lower the seed vigor level, the greater was the plant population required. High vigor seeds also compensated the effects of low plant populations.
\end{abstract}

Key words: Avena strigosa, biological yield, leaf area, growth rate

\section{INTRODUÇÃO}

O sistema plantio direto ou semeadura direta na palha já é hoje uma prática totalmente consagrada no Brasil, e por suas características de proteção do solo contra a erosão, pelo controle de invasoras, pelo aumento da fertilidade do solo, pela redução de custo de produção, e por possibilitar a exploração pastoril, tem sido adotado de forma crescente pelos produtores. Dentre as principais espécies utilizadas como cultura de cobertura salienta-se a aveia preta, por suas qualidades forrageiras, produção de massa verde, por ser de produção invernal criando condições para a semeadura dos cultivos de verão como soja e milho, além de oferecer forragem de qualidade no período de inverno (Carambula, 1977; Ruedell, 1995). A grande utilização desta espécie como uma planta de cobertura de inverno, e o elevado potencial para crescimento da área cultivada com a mesma, exigem grandes volumes de sementes, que de maneira geral tem apresentado baixa qualidade. Estima-se que o poder germinativo da maioria das sementes utilizadas para semeadura no Rio Grande do Sul, encontre-se em uma faixa entre 60 a $70 \%$.

O vigor das sementes afeta diretamente a performance de sementes para regenerar a cultura, podendo influenciar muitos aspectos de desempenho da mesma. Os efeitos de vigor de sementes sobre a taxa e a uniformidade de emergência, a emergência total, e o estabelecimento de estandes são bem documentados (Schuch \& Lin, 1982a; Schuch, 1999). Esses fatores podem influenciar a acumulação de matéria seca, e assim afetar o rendimento. Em geral, nos trabalhos onde são

${ }^{1}$ Parte da Tese de Doutorado do primeiro autor apresentada à FAEM/UFPel - Pelotas, RS. 
reportados efeitos significativos de vigor de sementes sobre o rendimento de sementes em culturas anuais, os efeitos, normalmente, estão associados com densidades populacionais em níveis subótimos (Schuch \& Lin, 1982b), ou em semeaduras mais tardias do que o normal (Khah et al., 1989). Por outro lado, Burris (1976) e Roberts (1986) sugeriram que a relação entre o vigor de sementes e o rendimento, é dependente do rendimento ser avaliado pela colheita no estágio vegetativo ou reprodutivo. TeKrony \& Egli (1991), também, concluíram que, o efeito do vigor de sementes sobre o rendimento do produto econômico, é dependente do estágio em que a cultura é colhida. Culturas cuja colheita é feita durante o crescimento vegetativo ou crescimento reprodutivo precoce têm, usualmente, mostrado uma relação consistente e positiva entre o vigor de sementes e o rendimento. Entretanto, para aquelas culturas cuja colheita é feita na maturação, geralmente não tem ocorrido relação entre o vigor de sementes e o rendimento, sob condições normais de cultivo. Assim, o vigor de sementes pode afetar o crescimento inicial das culturas, sendo que 0 efeito tende a se reduzir com a evolução do crescimento (TeKrony et al., 1989). A cultura de aveia preta visando a cobertura de solo para plantio direto e/ou pastejo enquadra-se entre aquelas culturas de colheita no estágio vegetativo ou reprodutivo precoce, situações estas onde são esperados os maiores efeitos do vigor das sementes.

O uso de populações de plantas mais elevadas, em geral, proporcionam uma produção de matéria seca mais alta por unidade de área em etapas precoces de desenvolvimento, favorecendo uma mais rápida cobertura do solo, e uma redução da infestação por plantas daninhas, mostrando ainda tendência a rendimentos mais altos (Carambula, 1977). Desse modo, seria de grande interesse avaliar a possibilidade de compensar as desvantagens iniciais da emergência mais lenta e do mais lento crescimento inicial mostrado pelas plantas originadas de sementes de menor vigor, pelo menos em parte, pela utilização de maiores densidades de semeadura, resultantes em maiores populações de plantas, para a cultura da aveia preta cujo cultivo se destina a utilização antes da maturação das sementes.

O presente trabalho teve por objetivo avaliar o efeito do vigor das sementes de duas cultivares de aveia preta sobre a evolução do crescimento da cultura, e a possibilidade de compensar o menor vigor pelo aumento na população de plantas.

\section{MATERIAL E MÉTODOS}

O experimento foi conduzido em condições de campo, no Centro Agropecuário da Palma, pertencente a Universidade Federal de Pelotas - CAP/UFPel, localizado no município do Capão de Leão - RS. O CAP/ UFPel está localizado na região fisiográfica denominada Encosta do Sudeste do Estado do Rio Grande do Sul, e situado a $31^{\circ} 45^{\prime} 45^{\prime \prime}$ de latitude Sul, $52^{\circ} 19^{\prime} 55^{\prime \prime}$ de longitude Oeste de Greenwich.

O solo da região onde foi instalado o experimento pertence à Unidade de Mapeamento "Matarazo", Brunizem Avermelhado na classificação brasileira e, Hapludalf na classificação de taxonomia de solos americana "USA Soil Taxonomy". Os resultados da análise de solo realizada no Laboratório de Análise de Solos, do Departamento de Solos da Faculdade de Agronomia "Eliseu Maciel", da Universidade Federal de Pelotas, conforme as normas da ROLAS (Comissão de Fertilidade

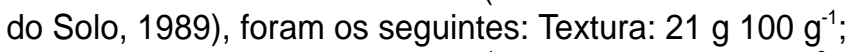

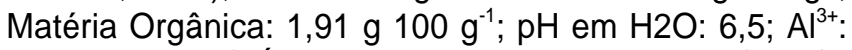
zero $\mathrm{cmol}_{\mathrm{c}} \mathrm{dm}^{-3}$; Índice SMP: 6,9 ; $\mathrm{Na}: 17 \mathrm{mg} \mathrm{kg}^{-1} ; \mathrm{Ca}^{2+}$ : $4,5 \mathrm{cmol}_{\mathrm{c}}^{\mathrm{c}} \mathrm{dm}^{-3} ; \mathrm{Mg}^{2+}: 1,8 \mathrm{cmol}_{\mathrm{c}} \mathrm{dm}^{-3} ; \mathrm{P}: 9,1 \mathrm{mg} \mathrm{kg}^{-1}$; $\mathrm{K}: 111 \mathrm{mg} \mathrm{kg}^{-1}$.

Foram testados em uma combinação fatorial, duas cultivares de aveia preta (Avena strigosa Schreb), três níveis de vigor de sementes e três densidades de semeadura, utilizando o delineamento experimental de blocos ao acaso, com quatro repetições. As parcelas foram constituídas por 10 linhas de 5 metros de comprimento, espaçadas de 23 centímetros. As cultivares utilizadas foram EMBRAPA 29 (Garoa) e EMBRAPA 140 (Campeira-Mor), ambas recomendada para cultivo nos estados do Rio Grande do Sul, Santa Catarina e Paraná. Os níveis alto, médio e baixo vigor, corresponderam a percentagens de germinação de $100 \%, 85 \%$ e $75 \%$, respectivamente. Os níveis médio e baixo vigor foram obtidos pela técnica de hidrotermoterapia modificada (Bhattacharyya et al., 1985), através da imersão das sementes de um lote de alta qualidade em água aquecida a $50^{\circ} \mathrm{C}$ por 150 minutos, e $55^{\circ} \mathrm{C}$ por 60 minutos, respectivamente. O nível alto vigor foi obtido pela utilização de sementes sem tratamento térmico. As populações de plantas foram de 150,300 e 450 plantas $\mathrm{m}^{-2}$, obtidas por ajustes nas densidades de semeadura em função das percentagens de germinação das sementes e das populações de plantas desejadas.

A semeadura foi realizada em $04 / 07 / 96$, sobre solo corrigido, e sob sistema convencional de preparo de solo, utilizando semeadora de parcelas. A adubação foi realizada a lanço com posterior incorporação com grade de discos, de acordo com a análise do solo e recomendação da ROLAS para culturas forrageiras de inverno, tendo sido aplicado na semeadura $12,5 \mathrm{~kg} \mathrm{ha}^{-1}$ de $\mathrm{N}, 50 \mathrm{~kg} \mathrm{ha}^{-1}$ de $\mathrm{P}_{2} \mathrm{O}_{5}$ e $50 \mathrm{~kg} \mathrm{ha}^{-1}$ de $\mathrm{K}_{2} \mathrm{O}$. A adubação de cobertura constou de $40 \mathrm{~kg} \mathrm{ha}^{-1}$ de N, aplicada aos 40 dias após a emergência. Para o controle de plantas invasoras foi aplicado durante o perfilhamento o herbicida 2,4-D (amina), na dosagem de 1,5 I ha ${ }^{-1}$ do produto comercial. No emborrachamento, estádio de crescimento 10 (Large, 1954), foi aplicado o fungicida Tebuconazole e o inseticida Permetrina em mistura de tanque, nas dosagens de $750 \mathrm{~g} \mathrm{ha}^{-1}$ e $50 \mathrm{ml} \mathrm{ha}^{-1}$, para o controle de ferrugem da folha e lagarta da folha, respectivamente. 
As determinações experimentais constaram de coletas de plantas realizadas em cinco épocas durante 0 ciclo da cultura, realizadas aos 29, 50, 75, 113 e 135 dias após emergência (DAE), que corresponderam respectivamente aos estádios $3.1,5.3,8.6$, segundo a escala de Haun (1973), início da antese e da maturação de colheita. Em cada coleta foram cortadas ao nível do solo todas as plantas presentes em um metro de fileira, onde foram realizadas determinações de área foliar, utilizando um determinador fotoelétrico que propicia leitura direta do valor, e determinações de matéria seca utilizando o método de diferença de peso após secagem em estufa a $55^{\circ} \mathrm{C}$ por 72 horas. Com os valores de área foliar e matéria seca foram determinados diversos parâmetros, cuja metodologia está descrita em Gardner et al. (1985), que foram: Índice de Área Foliar (IAF), Taxa de Crescimento da Cultura - TCC ( $\left.\mathrm{kg} \mathrm{ha}^{-1} \mathrm{dia}^{-1}\right)$, Taxa de Crescimento Relativo - TCR $\left(\mathrm{g} \mathrm{g}^{-1} \mathrm{dia}^{-1}\right)$, e Taxa de Assimilação Líquida - TAL ( $\left.\mathrm{g} \mathrm{dm}^{-2} \mathrm{dia}^{-1}\right)$. Semanalmente foi determinado o estágio de crescimento, em dez plantas, em todas as parcelas com população de 300 plantas $\mathrm{m}^{-2}$, utilizando a escala de Haun (1973).

Os dados experimentais foram submetidos a análise da variância sendo os efeitos dos tratamentos e interações avaliados pelo teste $F$, enquanto que as médias dos tratamentos foram comparadas entre si pelo teste de Duncan, a 5\%. Quando significativos pelo teste F, foram realizadas análises de regressão polinomiais para os efeitos de níveis de vigor de sementes e de populações de plantas, para todas as variáveis avaliadas.

\section{RESULTADOS E DISCUSSÃO}

\section{Produção de matéria seca}

A análise da variância indicou que para a produção de matéria seca não ocorreu interação entre o fator cultivares e o vigor de sementes ou a população de plantas, indicando que as duas cultivares apresentaram comportamento semelhante tanto para a variação no nível de qualidade de sementes, como para a população de plantas. Os efeitos da variação nos níveis de vigor das sementes e nas populações de plantas foram independentes, nos cinco estádios de crescimento.

A produção de matéria seca (TABELA 1) apresentou uma evolução progressiva com o avanço do crescimento da cultura, tendo produzido valores médios de 153, 563 e $2673 \mathrm{~kg} \mathrm{ha}^{-1}$ aos 29, 50 e 75 dias após a emergência - DAE, respectivamente, atingindo valores máximos em torno de $8642 \mathrm{~kg} \mathrm{ha}^{-1}$, por ocasião da antese (113 DAE), sofrendo redução para o período de colheita (135 DAE). Os valores de produção de matéria seca obtidos por ocasião do florescimento mostraram-se superiores aos obtidos em alguns ensaios de competição de linhagens de aveia preta, conduzidos no RS e SC. Entretanto, produtividades acima de $8500 \mathrm{~kg} \mathrm{ha}^{-1} \mathrm{de}$ matéria seca também são comuns nesse tipo de experimentação no sul do Brasil. Gaudêncio (1995) obteve produções de até $14627 \mathrm{~kg} \mathrm{ha}^{-1}$ de matéria seca.

Os diferentes níveis de vigor de sementes e de população de plantas causaram diferenças na produção de matéria seca, sendo que este efeito manifestou-se aos 29 DAE e aos 75 DAE, tendo a intensidade do efeito sido reduzido com o avanço do crescimento das plantas (TABELA 1). Assim, a diferença na produção de matéria seca entre as plantas provenientes de sementes de alto e baixo vigor, que era de $31 \%$ aos $29 \mathrm{DAE}$, caiu para $15 \%$ aos 75 DAE. No mesmo sentido, a diferença de produção de matéria seca entre a mais alta e a mais baixa população de plantas foi de $37 \%, 25 \%$ e $16 \%$, aos 29 , 50 e 75 DAE, respectivamente. Para as coletas posteriores não se manifestaram efeitos devido a variação na qualidade de sementes e na população de plantas. Assim, as diferenças no vigor das sementes e na população de plantas afetaram o crescimento inicial da

TABELA 1 - Produção de matéria seca de plantas de aveia preta (médias de duas cultivares), em decorrência de diferentes níveis de vigor de sementes e de populações de plantas, em cinco épocas do desenvolvimento, CAP/UFPel, Capão do Leão-RS.

\begin{tabular}{|c|c|c|c|c|c|}
\hline \multirow{2}{*}{ Tratamentos } & Época 1 & Época 2 & Época 3 & Época 4 & Época 5 \\
\hline & $29 \mathrm{DAE}^{*}$ & $50 \mathrm{DAE}$ & $75 \mathrm{DAE}$ & $113 \mathrm{DAE}$ & $135 \mathrm{DAE}$ \\
\hline Níveis de vigor & \multicolumn{5}{|c|}{ - kg ha-1 } \\
\hline Alto & $180 \mathrm{a}$ & 558 a & $2830 \mathrm{a}$ & $8715 \mathrm{a}$ & $7938 \mathrm{a}$ \\
\hline Médio & $154 \mathrm{~b}$ & $612 \mathrm{a}$ & 2770 a & 8658 a & $7823 \mathrm{a}$ \\
\hline Baixo & $125 c$ & $514 \mathrm{a}$ & $2420 \mathrm{~b}$ & $8553 a$ & $7390 \mathrm{a}$ \\
\hline \multicolumn{6}{|c|}{ Populações (pl m-2) } \\
\hline 450 & $192 \mathrm{a}$ & $645 \mathrm{a}$ & 2960 a & $9104 \mathrm{a}$ & $7984 \mathrm{a}$ \\
\hline 300 & $146 \mathrm{~b}$ & $560 \mathrm{ab}$ & $2580 \mathrm{~b}$ & $8638 a$ & $7813 a$ \\
\hline 150 & $121 \mathrm{~b}$ & $483 \mathrm{~b}$ & $2480 \mathrm{~b}$ & $8184 \mathrm{a}$ & $7354 \mathrm{a}$ \\
\hline Médias & $153 \mathrm{E}$ & $563 \mathrm{D}$ & $2673 \mathrm{C}$ & $8642 \mathrm{~A}$ & $7717 \mathrm{~B}$ \\
\hline C.V.(\%) & 28,50 & 35,00 & 21,39 & 21,65 & 21,03 \\
\hline
\end{tabular}

${ }^{*} \mathrm{DAE}$ - Dias após a emergência

Médias seguidas da mesma letra minúscula na coluna, dentro de níveis de vigor e de população de plantas, e maiúscula na linha, não diferem estatisticamente pelo teste de Duncan a $5 \%$. 
cultura, tendo seus efeitos reduzido com a evolução do crescimento. Resultados semelhantes foram obtidos por Burris (1976), Roberts (1986), TeKrony \& Egli (1991) e TeKrony et al. (1989) para efeitos de vigor de sementes, e por Oliveira et al.(1998a) e Oliveira et al. (1998b) para efeitos de variações na popualção de plantas.

A magnitude dos efeitos da variação nos níveis de vigor de sementes e da população de plantas sobre a produção de matéria seca, pode ser observada na TABELA 1, onde a diferença entre o maior e o menor nível de vigor de sementes atingiu o valor de $55 \mathrm{~kg} \mathrm{ha}^{-1}$ já aos 29 DAE, e $410 \mathrm{~kg} \mathrm{ha}^{-1}$ aos 75 DAE. Na mesma tabela constata-se que, o uso de uma população de plantas mais alta provocou acréscimos de 71 e $162 \mathrm{~kg} \mathrm{ha}^{-1}$, aos 29 e 50 DAE em relação a população mais baixa, respectivamente, atingindo uma diferença de $480 \mathrm{~kg} \mathrm{ha}^{-1}$ aos 75 DAE. A aveia preta é uma espécie de inverno muito versátil, podendo ser utilizada para a produção de forragem, cobertura do solo e adubação verde. Assim, para utilização como uma cultura forrageira, o início do pastejo será realizado a partir do perfilhamento pleno (Denardin \& Kochhann, 1993); para fenação o momento do corte ocorrerá quando a aveia apresentar altura em torno de $30 \mathrm{~cm}$, ou mais ou menos 60 dias após a emergência das plantas (Santos et al., 1990) e, para cobertura do solo, o manejo mecânico ou a dessecação da aveia preta visando a semeadura das culturas de verão deverão ser feitos no máximo até a época da floração (Fernandes et al., 1991). Assim, por ser colhida durante o crescimento vegetativo ou crescimento reprodutivo precoce nos sistemas de utilização mais difundidos, a espécie coloca-se entre as culturas de mais provável ocorrência de relacionamentos consistentes entre vigor de sementes e rendimento de produto econômico. Dessa forma, os resultados demonstram a importância da utilização de sementes de alta qualidade para o cultivo da aveia preta, bem como de altas populações de plantas, fatores que isoladamente melhoram seu desempenho, proporcionando rápida cobertura do solo, oferta precoce e maior de forragem e maior produção de matéria seca para a semeadura direta de cultivos de verão.

O efeito conjunto da variação no nível de vigor das sementes e da população de plantas pode ser observado na Figura 1. Aos $29 \mathrm{DAE}$, a combinação de sementes de alto vigor com a população mais alta propiciou os mais altos rendimentos de matéria seca, atingindo produção em torno de $230 \mathrm{~kg} \mathrm{ha}^{-1}$. Por outro lado, sementes de baixo vigor combinado com baixas e médias populações produziram apenas cerca de $100 \mathrm{~kg} \mathrm{ha}^{-1}$ de matéria seca, representando uma diferença em torno de $130 \mathrm{~kg} \mathrm{ha}^{-1}$ entre os tratamentos. A utilização de sementes de alto vigor combinado com a população de $300 \mathrm{pl} \mathrm{m}^{-2}$, propor-cionou rendimentos similares aos de sementes de médio vigor combinado com populações de 300 e $450 \mathrm{pl} \mathrm{m}^{-2}$. As sementes de baixo vigor necessitaram da mais alta população de plantas para obter rendimentos semelhantes.

Aos $75 \mathrm{DAE}$, a produção de matéria seca das
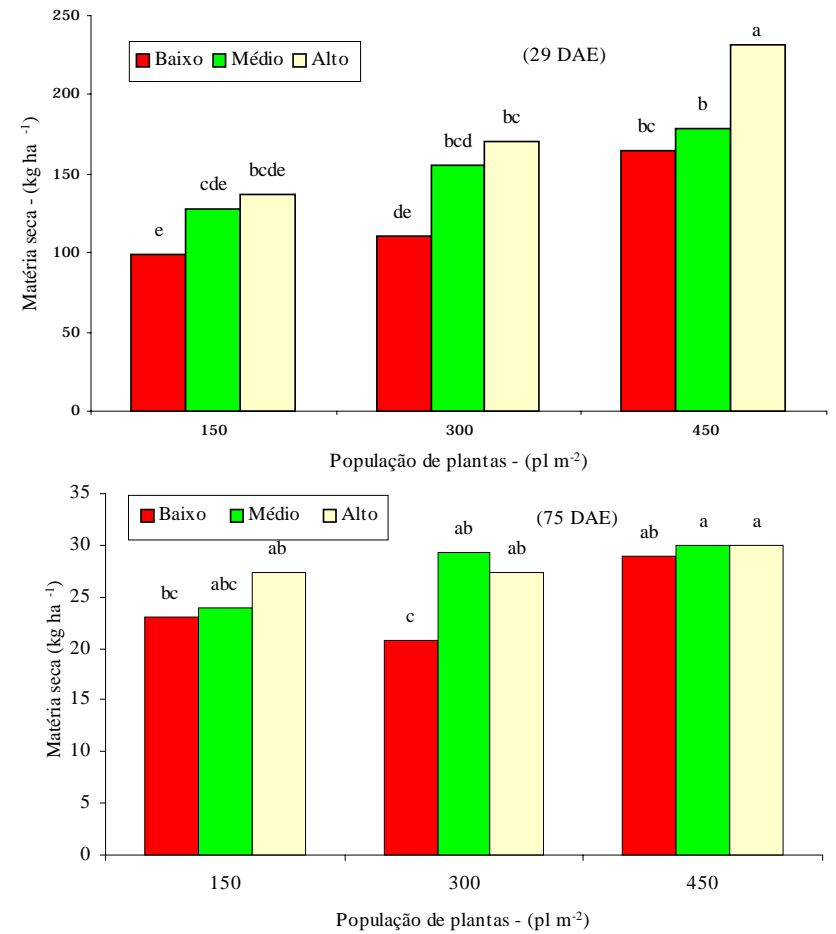

Figura 1 - Produção de matéria seca de aveia preta (médias de duas cultivares), em decorrência de níveis de vigor de sementes e de populações de plantas, aos 29 e 75 dias após a emergência (DAE), CAP/UFPel, Capão do Leão-RS.

plantas provenientes de sementes de maior vigor mostrouse independente da população de plantas, tendo atingido valores de até $3000 \mathrm{~kg} \mathrm{ha}^{-1}$, enquanto que a combinação baixo vigor de sementes com baixa população de plantas produziu valores em torno de $2300 \mathrm{~kg} \mathrm{ha}^{-1}$, representando assim uma diferença de até $700 \mathrm{~kg} \mathrm{ha}^{-1}$ de matéria seca entre os tratamentos. Similarmente ao que ocorreu aos $29 \mathrm{DAE}$, sementes de baixo vigor necessitaram populações de $450 \mathrm{pl} \mathrm{m}^{-2}$ para a obtenção de rendimentos de matéria seca similares aos obtidos pelas plantas provenientes de sementes de alto vigor.

Dessa forma, observa-se um significativo efeito compensatório exercido pela população de plantas, de modo que o efeito de um baixo vigor de sementes poderia, em parte, ser compensado pela elevação na população. Quanto mais baixo o nível de vigor das sementes, mais alta deve ser a população de plantas para atingir níveis semelhantes de produção de matéria seca. Essa constatação é de extrema importância considerando o cultivo da aveia preta, uma vez que as sementes disponíveis para a semeadura no RS apresentam, em geral, níveis de qualidade fisiológica relativamente baixos, com um poder germinativo de $60-70 \%$ para a maioria dos lotes. Assim, os efeitos dessa baixa qualidade de sementes poderia, em parte, ser compensado pela elevação da densidade de semeadura, com vistas a proporcionar o cultivo da espécie sob altos níveis populacionais. Por outro lado, reforça o benefício da utilização de sementes de alta qualidade, uma vez que possíveis deficiências na população de plantas, causadas 
por condições ambientais adversas por ocasião da instalação da cultura no campo, poderiam ser compensadas pelo uso de sementes de alta qualidade, não prejudicando o desempenho da cultura.

\section{Índice de área foliar}

O índice de área foliar foi crescente com a evolução do crescimento das plantas atingindo um IAF máximo em torno de 4,10 na média das duas cultivares, aos $75 \mathrm{DAE}$, decrescendo para valores em torno de 1,0 por ocasião da antese (TABELA 2). Por ocasião da maturação já não haviam folhas verdes nas plantas.

De maneira geral, não se verificaram efeitos interativos entre os fatores estudados, com exceção das respostas diferenciadas observadas entre as cultivares para a variação no nível de vigor aos 75 e 113 DAE. Assim, enquanto que aos 29 DAE o uso de sementes de baixa qualidade provocou redução de $33 \%$ no IAF das duas cultivares, nas fases posteriores do ciclo, a cultivar Embrapa 140 não sofreu variações no IAF devido a variação no nível de vigor das sementes. Já na cultivar Embrapa 29, as diferenças em qualidade das sementes provocaram diferenças de IAF de $25 \%$ e $31 \%$, aos 75 e $113 \mathrm{DAE}$, respectivamente.

$\mathrm{Na}$ Figura 2, observam-se os efeitos combinados dos níveis de vigor de sementes e das populações de planta. Aos $29 \mathrm{DAE}$, sementes de alto vigor combinado com a mais alta população de plantas proporcionaram níveis de IAF de 0,67 , enquanto a combinação sementes de baixo vigor com a mais baixa população de plantas produziu IAF de apenas 0,26 . As sementes de baixo vigor necessitaram da mais alta população de plantas para obtenção de IAFs similares aos proporcionados pelas sementes de alto e médio vigor na população de $300 \mathrm{pl} \mathrm{m}^{-2}$. Aos 75 DAE, a combinação alto vigor de sementes com a população de $450 \mathrm{pl} \mathrm{m}^{-2}$ apresentou um dos valores mais altos de IAF $(4,64)$, enquanto a combinação sementes de baixo vigor com a menor população esteve entre os valores mais baixos de IAF $(3,38)$. Sementes de alto vigor, mesmo com população de $150 \mathrm{pl} \mathrm{m}^{-2}$, proporcio-naram um valor de IAF semelhante aos obtidos na população de 450 $\mathrm{pl} \mathrm{m}{ }^{-2}$, para o qual sementes de médio vigor necessitaram populações de $300 \mathrm{pl} \mathrm{m}^{-2}$ ou superior. As sementes de baixo vigor necessitaram populações de $450 \mathrm{pl} \mathrm{m}^{-2}$ para obtenção de valores similares.

De maneira geral, o índice de área foliar evoluiu
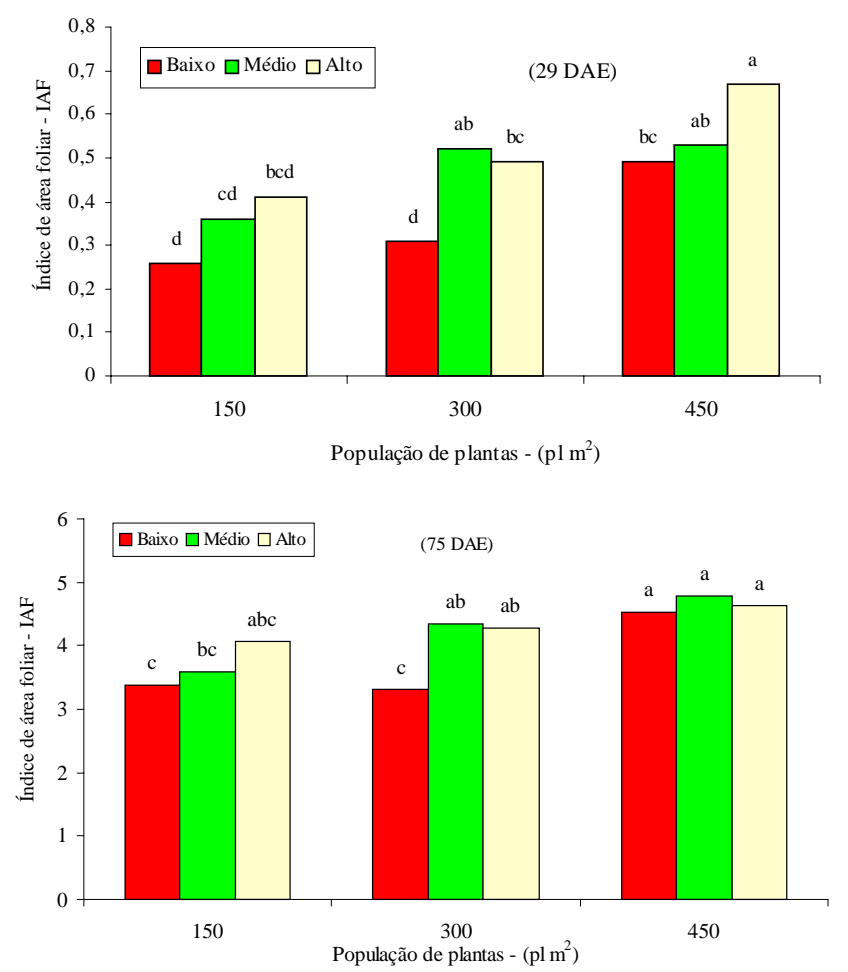

Figura 2 - Índice de área foliar de aveia preta (médias de duas cultivares), em decorrência de níveis de vigor de sementes e de populações de plantas, aos 29 e 75 dias após a emergência (DAE), CAP/UFPel, Capão do Leão-RS.

TABELA 2 - Índice de área foliar (IAF) de plantas de aveia preta (médias de duas cultivares), em decorrência de diferentes níveis de vigor de sementes e populações de plantas, em quatro épocas do desenvolvimento, CAP/UFPel, Capão do Leão-RS.

\begin{tabular}{|c|c|c|c|c|c|c|}
\hline \multirow{2}{*}{$\begin{array}{l}\text { Tratamentos } \\
\text { Níveis de vigor }\end{array}$} & \multirow[t]{2}{*}{$\begin{array}{l}\text { Época } 1 \\
29 \mathrm{DAE}^{*}\end{array}$} & \multirow[t]{2}{*}{$\begin{array}{l}\text { Época } 2 \\
50 \text { DAE }\end{array}$} & \multicolumn{2}{|c|}{$\begin{array}{l}\text { Época } 3 \\
75 \text { DAE }\end{array}$} & \multicolumn{2}{|c|}{$\begin{array}{l}\text { Época } 4 \\
113 \text { DAE }\end{array}$} \\
\hline & & & Embrapa 29 & 9 Embrapa 140 & Embrapa 29 & Embrapa 140 \\
\hline Alto & $0,52 \mathrm{a}$ & $1,38 \mathrm{a}$ & $4,58 \mathrm{a}$ & $4,07 \mathrm{a}$ & $1,31 \mathrm{a}$ & $0,95 \mathrm{a}$ \\
\hline Médio & $0,47 \mathrm{a}$ & $1,48 \mathrm{a}$ & $4,22 \mathrm{a}$ & $4,26 \mathrm{a}$ & $0,96 \mathrm{~b}$ & $0,89 a$ \\
\hline Baixo & $0,35 \mathrm{a}$ & $1,22 \mathrm{a}$ & $3,42 b$ & $4,07 \mathrm{a}$ & $0,91 \mathrm{~b}$ & $1,10 \mathrm{a}$ \\
\hline \multicolumn{7}{|c|}{ Populações (pl m²) } \\
\hline 450 & $0,56 \mathrm{a}$ & $1,59 \mathrm{a}$ & \multicolumn{2}{|c|}{$4,66 \mathrm{a}$} & \multicolumn{2}{|c|}{$1,00 \mathrm{a}$} \\
\hline 300 & $0,44 \mathrm{~b}$ & $1,35 \mathrm{ab}$ & \multicolumn{2}{|c|}{$3,98 b$} & \multicolumn{2}{|c|}{$1,02 \mathrm{a}$} \\
\hline 150 & $0,34 \mathrm{c}$ & $1,14 \mathrm{~b}$ & \multicolumn{2}{|c|}{$3,68 b$} & \multicolumn{2}{|c|}{$1,05 \mathrm{a}$} \\
\hline Médias & $0,45 \mathrm{D}$ & $1,36 \mathrm{~B}$ & \multicolumn{2}{|c|}{$4,10 \mathrm{~A}$} & \multicolumn{2}{|c|}{$1,02 \mathrm{C}$} \\
\hline C.V.(\%) & 33,32 & 32,68 & \multicolumn{2}{|c|}{19,37} & \multicolumn{2}{|c|}{31,15} \\
\hline
\end{tabular}

*DAE - Dias após a emergência.

Médias seguidas da mesma letra minúscula na coluna, dentro de níveis de vigor e de população de plantas, e maiúscula na linha, não diferem estatisticamente pelo teste de Duncan a $5 \%$. 
de modo similar a produção de matéria seca até $75 \mathrm{DAE}$, ocorrendo, no entanto, severa redução a partir desse momento até a antese, onde foram obtidos os maiores valores de produção de matéria seca. Também Lopes (1973) observou na cultura do milho que o IAF progrediu de forma similar à progressão da matéria seca total, não havendo, no entanto, correspondência entre o máximo IAF e a máxima taxa de crescimento da cultura

\section{Índices de crescimento da cultura}

Os valores dos diversos índices de crescimento da cultura estão relacionados nas TABELAS 3 e 4 . A taxa de crescimento da cultura (TCC) foi aumentando com a evolução do crescimento do cultivo, alcançando os valores máximos no período entre 75 a $113 \mathrm{DAE}$, onde chegou a atingir valores acima de $160 \mathrm{~kg} \mathrm{ha}^{-1} \mathrm{dia}^{-1}$. Alguns trabalhos tem avaliado taxas de crescimento da cultura da aveia no RS, tendo sido determinado valores máximos da TCC de até $97,8 \mathrm{~kg} \mathrm{ha}^{-1} \mathrm{dia}^{-1}$ (Floss et al., 1995). Essas taxas, no entanto, foram determinadas considerando o ciclo completo da cultura.

Nos períodos desde a emergência até 29 DAE e entre 50 e $75 \mathrm{DAE}$, as taxas de crescimento da cultura foram progressivamente crescentes com o aumento no nível de vigor das sementes. O efeito do vigor das sementes foi sendo reduzido de intensidade com o avanço do ciclo da cultura, sendo $30 \%$ e $16 \%$ as diferenças entre os níveis extremos de vigor para os períodos 1 e 3 , respectivamente. Durante o período compreendido entre 50 a $75 \mathrm{DAE}$, as diferenças na qualidade de sementes provocaram diferença na TCC de até $15 \mathrm{~kg} \mathrm{ha}^{-1} \mathrm{dia}^{-1}$. A elevação na população de plantas provocou elevação na taxa de crescimento da cultura, até o período entre 50 a $75 \mathrm{DAE}$, tendo as diferenças desaparecido com o avanço do ciclo da cultura. Entre 50 a 75 DAE, as populações extremas diferiram na TCC em 13,2 $\mathrm{kg} \mathrm{ha}^{-1} \mathrm{dia}^{-1}$.

A taxa de crescimento relativo (TCR) tendeu a decrescer com a evolução do crescimento após $50 \mathrm{DAE}$, apresentando inclusive valores negativos para o período pós-antese. Lopes (1973) trabalhando com a cultura do milho no Rio Grande do Sul, constatou os maiores valores para a TCR (acima de 2,0 $\mathrm{g} \mathrm{g}^{-1} \mathrm{dia}^{-1}$ ) logo no início do ciclo da cultura, observando uma severa redução entre, aproximadamente, o 25 e o 30 dia após emergência, atingindo cerca de $0,25 \mathrm{~g} \mathrm{~g}^{-1} \mathrm{dia}^{-1}$. Aos 40 DAE atingiu valores de aproximadamente $0,10 \mathrm{~g} \mathrm{~g}^{-1} \mathrm{dia}^{-1}$, reduzindo lentamente após este período. Barni et al. (1995), também no Rio Grande do Sul, observaram que a TCR na cultura do girassol foi alta no início do ciclo, diminuindo gradativamente até a maturação fisiológica. Em um dos anos da experimentação, entretanto, os autores também constataram uma redução acentuada até 38 DAE. As reduções na TCR, que normalmente ocorrem com o avanço no ciclo das culturas, são devidas ao aumento

TABELA 3 - Taxa de crescimento da cultura (TCC), taxa de crescimento relativo (TCR) e taxa de assimilação líquida (TAL), da cultura da aveia preta (médias de duas cultivares) em decorrência de diferentes níveis de vigor de sementes, em 5 períodos de desenvolvimento da cultura, CAP/UFPel, Capão do Leão-RS.

\begin{tabular}{|c|c|c|c|c|c|}
\hline $\begin{array}{l}\text { Níveis } \\
\text { de vigor }\end{array}$ & $\begin{array}{r}\text { Período } 1 \\
\left(\text { Emerg. a } 29 \mathrm{DAE}^{*}\right)\end{array}$ & $\begin{array}{c}\text { Período } 2 \\
\text { (29 a } 50 \text { DAE })\end{array}$ & $\begin{array}{c}\text { Período } 3 \\
(50 \text { a } 75 \text { DAE })\end{array}$ & $\begin{array}{c}\text { Período } 4 \\
(75 \text { a } 113 \text { DAE })\end{array}$ & $\begin{array}{c}\text { Período } 5 \\
\text { (113 a } 135 \text { DAE })\end{array}$ \\
\hline \multicolumn{6}{|c|}{ - } \\
\hline Alto & $6,19 \mathrm{a}$ & $18,03 \mathrm{a}$ & $95,47 \mathrm{a}$ & $155,33 \mathrm{a}$ & $-35,35 a$ \\
\hline Médio & $5,31 b$ & $21,82 \mathrm{a}$ & $90,97 \mathrm{ab}$ & $154,78 \mathrm{a}$ & $-42,75$ a \\
\hline Baixo & $4,31 \mathrm{c}$ & 18,69 a & $80,40 \mathrm{~b}$ & $162,06 \mathrm{a}$ & $-51,34 \mathrm{a}$ \\
\hline Médias & $5,27 \mathrm{C}$ & $19,51 \mathrm{C}$ & 88,94 B & $157,39 \mathrm{~A}$ & $-43,15 \mathrm{D}$ \\
\hline C.V.(\%) & 28,49 & 43,37 & 21,88 & 30,93 & 35,40 \\
\hline \multicolumn{6}{|c|}{ - Taxa de Crescimento Relativo - TCR $\left(\mathrm{g} \mathrm{g}^{-1} \mathrm{dia}^{-1}\right)$} \\
\hline Alto & - & $0,051 \mathrm{~b}$ & $0,072 \mathrm{a}$ & $0,029 \mathrm{~b}$ & $-0,004 \mathrm{a}$ \\
\hline Médio & - & $0,063 \mathrm{a}$ & $0,068 \mathrm{a}$ & $0,031 a b$ & $-0,006 \mathrm{a}$ \\
\hline Baixo & - & $0,064 \mathrm{a}$ & $0,070 \mathrm{a}$ & $0,034 \mathrm{a}$ & $-0,007 \mathrm{a}$ \\
\hline Médias & - & $0,059 \mathrm{~B}$ & $0,070 \mathrm{~A}$ & $0,031 \mathrm{C}$ & $-0,005 \mathrm{D}$ \\
\hline C.V.(\%) & - & 24,90 & 15,42 & 22,90 & 1,13 \\
\hline \multicolumn{6}{|c|}{--- Taxa de Assimilação Líquida - TAL $\left(\mathrm{g} \mathrm{dm}^{2} \mathrm{dia}^{-1}\right)$-- } \\
\hline Alto & - & $0,019 \mathrm{~b}$ & 0,039 a & $0,072 \mathrm{a}$ & - \\
\hline Médio & - & $0,024 \mathrm{a}$ & $0,037 \mathrm{a}$ & 0,079 a & - \\
\hline Baixo & - & $0,025 \mathrm{a}$ & 0,038 a & 0,087 a & - \\
\hline Médias & - & $0,023 \mathrm{C}$ & 0,038 B & $0,079 \mathrm{~A}$ & - \\
\hline C.V.(\%) & - & 27,29 & 17,40 & 31,94 & - \\
\hline
\end{tabular}

*DAE- Dias após a emergência.

Médias seguidas da mesma letra minúscula na coluna e maiúscula na linha, não diferem estatisticamente pelo teste de Duncan a $5 \%$. 
gradual de tecidos não assimilatórios. Tanto no tratamento com maior vigor das sementes como com maior população de plantas observaram-se valores menores na TCR.

A taxa de assimilação líquida (TAL) (TABELAS 3 e 4) foi inversamente proporcional tanto ao aumento no vigor das sementes como ao aumento na população de plantas, respectivamente nos períodos 2 e 3 .

Tanto o IAF como a TCC apresentaram valores crescentes com a elevação do nível de qualidade das sementes e da população de plantas, até 75 DAE (TABELAS 2, 3 e 4). Já a TCR e TAL, apresentaram uma tendência de redução nos índices com o aumento nos níveis de vigor e de população. Isso mostra que embora a produtividade por unidade de área tenha aumentado com o acréscimo no vigor das sementes e da população de plantas, a produtividade, por unidade de matéria seca e por unidade de área foliar, reduziu com o aumento dos dois fatores. Khah et al. (1989) concluiram que, em condições agrícolas normais, pode ser esperado que as vantagens iniciais da emergência precoce e do mais rápido crescimento inicial, mostradas pelas plantas individuais, diminuam com o avanço no período de crescimento, em função de a competição interplanta por recursos de crescimento (água, nutrientes e especialmente sombreamento mútuo) iniciar mais cedo em cultivos derivados de sementes de melhor qualidade. Raciocínio similar pode ser feito para os efeitos de maiores populações de plantas, onde também a competição interplanta inicia mais cedo na estação de crescimento. Assim, as diferenças nas produções de matéria seca observadas até 75 DAE entre níveis de vigor de sementes e populações de plantas (TABELA 1), foram devidas as diferenças nas Taxas de Crescimento da Cultura - TCC, que ocorreram até o terceiro período de crescimento (TABELAS 3 e 4). A redução progressiva das diferenças observadas na produção de matéria seca, que ocorreu com a evolução do desenvolvimento das plantas, entre os níveis extremos de vigor de sementes e de populações de plantas (TABELA 1), justificam-se pelas também progressivas reduções nas diferenças entre as TCC, as quais, por sua vez, foram devidas as reduções nas Taxas de Crescimento Relativo - TCR ocorridas nos níveis mais altos de vigor de sementes e de populações de plantas (TABELAS 3 e 4).

\section{Fenologia de plantas}

A análise da variância indicou que não ocorreram interações entre os efeitos dos fatores cultivares e níveis de vigor de sementes durante a evolução do crescimento das plantas (dados não apresentados). Entretanto, os efeitos isolados de cultivares e níveis de vigor de sementes foram significativos, tendo as sementes de alto vigor e a cultivar Embrapa 140 proporcionado maior precocidade na média do período desde a emergência até

TABELA 4 - Taxa de crescimento da cultura (TCC), taxa de crescimento relativo (TCR) e taxa de assimilação líquida (TAL), da cultura da aveia preta (médias de duas cultivares) cultivada em diferentes populações de plantas, determinadas em 5 períodos de desenvolvimento da cultura, CAP/UFPel, Capão do Leão-RS.

\begin{tabular}{|c|c|c|c|c|c|}
\hline $\begin{array}{l}\text { Populações } \\
\left(\mathrm{pl} / \mathrm{m}^{2}\right)\end{array}$ & $\begin{array}{c}\text { Período } 1 \\
\left.\text { (Emerg. a } 29 \mathrm{DAE}^{*}\right)\end{array}$ & $\begin{array}{c}\text { Período } 2 \\
\text { (29 a } 50 \text { DAE) }\end{array}$ & $\begin{array}{c}\text { Período } 3 \\
\text { (50 a } 75 \text { DAE) }\end{array}$ & $\begin{array}{c}\text { Período } 4 \\
\text { (75 a } 113 \mathrm{DAE})\end{array}$ & $\begin{array}{c}\text { Período } 5 \\
\text { (113 a } 135 \text { DAE) }\end{array}$ \\
\hline & \multicolumn{5}{|c|}{ - } \\
\hline 450 & $6,61 \mathrm{a}$ & $21,58 \mathrm{a}$ & $97,35 \mathrm{a}$ & $161,45 \mathrm{a}$ & $-52,15 a$ \\
\hline 300 & $5,03 \mathrm{~b}$ & $19,71 \mathrm{a}$ & $85,37 \mathrm{~b}$ & 159,56 a & $-38,88 \mathrm{a}$ \\
\hline 100 & $4,17 \mathrm{~b}$ & $17,24 \mathrm{a}$ & $84,12 \mathrm{~b}$ & $151,17 \mathrm{a}$ & $-38,41 \mathrm{a}$ \\
\hline Médias & $5,27 \mathrm{C}$ & $19,51 \mathrm{C}$ & $88,94 \mathrm{~B}$ & $157,39 \mathrm{~A}$ & $-43,15 \mathrm{D}$ \\
\hline \multirow[t]{2}{*}{ C.V.(\%) } & 28,49 & 43,37 & 21,88 & 30,93 & 35,40 \\
\hline & \multicolumn{5}{|c|}{ 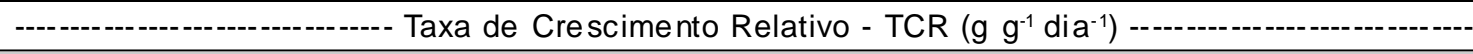 } \\
\hline 450 & - & $0,056 \mathrm{a}$ & $0,068 \mathrm{~b}$ & $0,030 \mathrm{a}$ & $-0,006$ a \\
\hline 300 & - & $0,062 \mathrm{a}$ & $0,067 \mathrm{~b}$ & $0,033 \mathrm{ab}$ & $-0,005 \mathrm{a}$ \\
\hline 150 & - & $0,059 a$ & $0,075 a$ & $0,032 \mathrm{a}$ & $-0,005 \mathrm{a}$ \\
\hline Médias & - & $0,059 \mathrm{~B}$ & $0,070 \mathrm{~A}$ & $0,032 \mathrm{C}$ & $-0,005 \mathrm{D}$ \\
\hline \multirow[t]{2}{*}{ C.V.(\%) } & - & 24,90 & 15,42 & 22,90 & 1,13 \\
\hline & \multicolumn{5}{|c|}{ - } \\
\hline 450 & - & $0,021 \mathrm{a}$ & $0,036 \mathrm{~b}$ & $0,075 \mathrm{a}$ & - \\
\hline 300 & - & $0,024 \mathrm{a}$ & $0,037 \mathrm{~b}$ & $0,083 a$ & - \\
\hline 100 & - & $0,023 a$ & $0,042 a$ & $0,079 a$ & - \\
\hline Médias & - & $0,023 \mathrm{C}$ & $0,038 \mathrm{~B}$ & $0,079 \mathrm{~A}$ & - \\
\hline C.V.(\%) & - & 27,29 & 17,40 & 31,64 & - \\
\hline
\end{tabular}

DAE- Dias após a emergência.

Médias seguidas da mesma letra minúscula na coluna e maiúscula na linha, não diferem estatisticamente pelo teste de Duncan a $5 \%$. 
o final da elongação do colmo. Na Figura 3, observa-se que a evolução do crescimento da cultura da aveia preta ajustou-se a um modelo linear, demonstrando a adequação da escala de Haun (1973), para a descrição de estágios de crescimento de cultivares de aveia preta nas condições climáticas do Rio Grande do Sul.

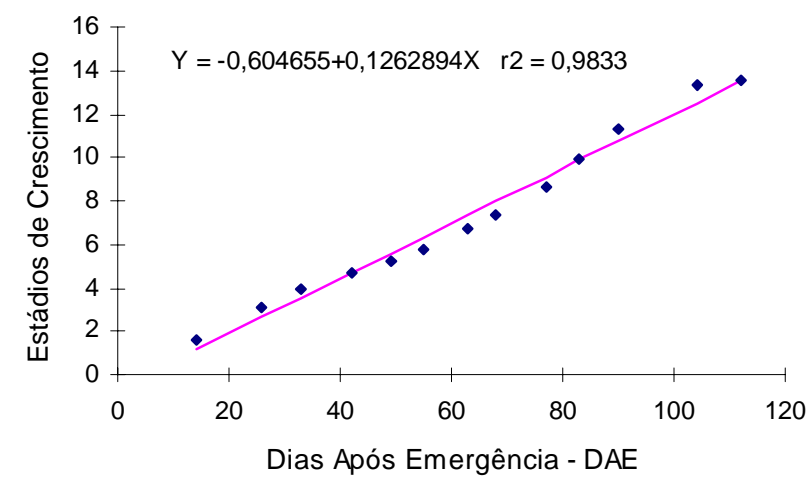

Figura 3 - Estádios de crescimento de aveia preta (médias de duas cultivares) ao longo da estação de crescimento, segundo escala de Haun (1973), CAP/UFPel, Capão do Leão-RS.

\section{CONCLUSÕES}

- Diferenças no vigor de sementes e na população de plantas causam variação na produção de matéria seca especialmente no início do período vegetativo, devido a diferenças na taxa de crescimento da cultura.

- O efeito do baixo vigor de sementes pode ser compensado pela elevação na população de plantas.

- O efeito das baixas populações de planta é compensado parcialmente pelo alto vigor de sementes.

- A escala de Haun (1973) mostra-se adequada para a descrição de estágios de crescimento de cultivares de aveia preta.

\section{REFERÊNCIAS BIBLIOGRÁFICAS}

BARNI, N.A.; BERLATO, M.A.; SANTOS, A.O.; SARTORI, G. Análise de crescimento do girassol em resposta a cultivares, níveis de adubação e épocas de semeadura. Pesquisa Agropecuária Gaúcha, v.1, p.167-184, 1995.

BHATTACHARYYA, S.; HAZRA, A.K.; SEN-MANDI, S. Accelerated ageing of seeds in hot water: germination characteristics of aged wheat seeds. Seed Science and Technology, v.13, p.683-690, 1985.

BURRIS, J.S. Seed: seedling vigor and field performance. Journal of Seed Technology, v.1, p.58-74, 1976.

CARAMBULA, M. Producción y manejo de pasturas sembradas. Montevideu: Hemisfério Sur, 1977.219p.

COMISSÃO DE FERTILIDADE DO SOLO. Recomendação de adubação e calagem para os Estados do Rio Grande do Sul e Santa Catarina. 2.ed. Passo Fundo: SBCS, Núcleo Regional Sul; EMBRAPA, CNPT, 1989. 128p.

DENARDIN, J.E.; KOCHHANN, R.A. Requisitos para implantação e manutenção do sistema plantio direto. In: EMBRAPA, CNPT. Plantio direto no Brasil. Passo Fundo, 1993. p.19-27.
FERNANDES, J.M.; FERNANDEZ, M.R.; KOCHANN, R.A.; SELLES, F.; ZENTNER, R.P. Manual de manejo conservacionista do solo para os estados do Rio Grande do Sul, Santa Catarina e Paraná. Passo Fundo: EMBRAPA, CNPT, 1991.69p. (Documento, 1).

FLOSS, E.L.; TISSOT, B.S.; RICHTER, C. Ensaio regional de rendimento de grãos de aveia, em Passo Fundo, 1994. In: REUNIÃO DA COMISSÃO SULBRASILEIRA DE PESQUISA DE AVEIA, 15., Guarapuava, 1995. Resultados experimentais. Guarapuava: Fundação Agrícola de Pesquisa Agropecuária, 1995. p.200-206.

GARDNER, F.P.; PEARCE, R.B.; MITCHELL, R.L. Physiology of crop plants. Ames: lowa State University Press, 1985. 321p.

GAUDÊNCIO, C.A. Ensaio de cultivares de aveia preta no norte do Paraná. In: REUNIÃO DA COMISSÃO SULBRASILEIRA DE PESQUISA DE AVEIA, 15., Guarapuava, 1995. Resultados experimentais. Guarapuava: Fundação Agrícola de Pesquisa Agropecuária, 1995. p.74-76.

HAUN, J.R. Visual quantification of wheat development. Agronomy Journal, v.65, p.116-119, 1973.

$\mathrm{KHAH}$, E.M.; ROBERTS, E.H.; ELLIS, R.H. Effects os seed ageing on growth and yield of spring wheat at different plant-population densities. Field Crops Research, v.20, p.175-190, 1989.

LARGE, E.C. Growth stages in cereals. Ilustration of Feeks scale. Plant Physiology, v.3, p.128-129, 1954.

LOPES, N.F. Análise de crescimento e conversão da energia solar em população de milho (Zea mays L.) em Viçosa, Minas Gerais. Viçosa, 1973. 61p. Dissertação (M.S.) - Universidade Federal de Viçosa.

OLIVEIRA, J.C.; OLIVEIRA, E.; SÁ, J.P.G.; ARAGÃO, A.A. Densidade de semeadura e rendimento forrageiro de aveia preta de ciclo precoce, em Londrina-PR, 1997. In: REUNIÃO DA COMISSÃO SULBRASILEIRA DE PESQUISA DE AVEIA, 18., Londrina, 1998. Resultados experimentais. Londrina: IAPAR, 1998a. p.90-91.

OLIVEIRA, J.C.; OLIVEIRA, E.; SÁ, J.P.G.; ARAGÃO, A.A. Densidade de semeadura e rendimento forrageiro de aveia preta de ciclo tardio, em Londrina-PR, 1997. In: REUNIÃO DA COMISSÃO SULBRASILEIRA DE PESQUISA DE AVEIA, 18., Londrina, 1998. Resultados experimentais. Londrina: IAPAR, 1998b. p.92-93.

ROBERTS, E.H. Quantifying seed deterioration. In: McDONALD JUNIOR, M.B.; NELSON, C.J. (Ed.). Physiology of seed deterioration. Madison: ASA/CSSA/SSSA, 1986. p.101-123. (Special Publication, 11).

RUEDELL, J. Plantio direto na região de Cruz Alta. Cruz Alta: FUNDACEP; FECOTRIGO, 1995. 133p.

SANTOS, H.S.; REIS, E.M.; PÖTTKER, D. Culturas de inverno para plantio direto no sul do Brasil. Passo Fundo: EMBRAPA, CNPT, 1990. 24p. (Circular Técnica, 3).

$\mathrm{SCHUCH}$, L.O.B. Vigor das sementes e aspectos da fisiologia da produção em aveia preta (Avena strigosa Schreb). Pelotas, 1999. 124p. Tese (Doutorado) - Universidade Federal de Pelotas.

SCHUCH, L.O.B.; LIN, S.S. Atraso na colheita sobre emergência no campo e desempenho de plantas de trigo. Pesquisa Agropecuária Brasileira, v.17, p.1585-1589, 1982a.

SCHUCH, L.O.B.; LIN, S.S. Efeito do envelhecimento rápido sobre o desempenho de sementes e de plantas de trigo. Pesquisa Agropecuária Brasileira, v.17, p.1163-1170, 1982b.

TeKRONY, D.M.; EGLI, D.B. Relationship of seed vigor to crop yield: a review. Crop Science, v.31, p.816-822, 1991.

TeKRONY, D.M.; EGLI, D.B.; WICKHAM, D.A. Corn seed vigor effect on no-tillage field performance: II. Plant growth and grain yield. Crop Science, v.29, p.1528-1531, 1989.

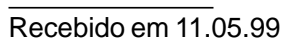

